\title{
Editorial Board Thoughts Column Getting to Yes: Stakeholder Buy-In for Implementing Emerging Technologies in Your Library
}

Ida Joiner

Have you ever wanted to implement new technologies in your library or resource center such as (drones, robotics, artificial intelligence, augmented/virtual reality/mixed reality, 3D printing, wearable technology, and others) and presented your suggestions to your stakeholders (board members, directors, managers, and other decision makers) only to be rejected based on "there isn't enough money in the budget," or "no one is going to use the technology," or "we like things the way that they are," then this column is for you.

I am very passionate about emerging technologies, how they are and will be used in libraries/ resource centers, and how librarians will be able to assist those who will be affected by these technologies. I recently published a book introducing emerging technologies in libraries. I came up with suggestions on how doing your research — including the questions below and those on the accompanying checklist - will prepare you to meet with your stakeholders and improve the likelihood of your emerging technology proposal being approved.

1. Who are your stakeholders and include them early on in the process? Determine who you stakeholders are, what their areas of expertise are, and how they can support your emerging technology projects. The most critical piece to getting your stakeholders on board to support your technology initiatives is addressing the question "What's in it for them?" This will get their attention and increase your odds to getting to say "yes" to your technology initiatives.

2. What are the costs? Research what your costs will be and create a budget. Find innovative ways to fund your initiatives by researching grants, strategic partnerships with others who might be interested in partnering with you, and locating other funding opportunities.

3. What are the risks? Identify any potential risks so that you are prepared to discuss how you will mitigate them when you meet with your stakeholders. Some potential risks that you might want to address are budget cost overruns or staffing issues such as a key person resigning or going on maternity or sick leave, or policies in place to deter patrons from trying to use the technology for criminal means.

Ida A. Joiner (ida.joiner@gmail.com), a member of LITA and the ITAL editorial board, is the Librarian at the Universal Academy School in Irving, Texas. She is the author of "Emerging Library Technologies: It's Not Just for Geeks" (Elsevier, August 2018). 
4. What is the timeline and key milestones? Address the timeline for when you want or need to implement these technologies? Have you planned for key milestones and possible delays such as funds not being available? You need to have a detailed timeline, from your first kickoff meeting with your initiative's team, to your stakeholder meeting where you present your proposal, to getting signoff on the project.

5. What training will you offer? Perform a needs assessment to determine who will need to be trained, what training you will offer, what your training costs will be, and who will pay for them. Once you have all of this in place, you will select the trainer(s) and the training model (such as "train the trainer") that you will use.

6. How will you market your technology initiatives? Will you rely on social media to market your technology initiatives? Will you collaborate with your marketing department for developing your message through press releases, websites, blogs, e-newsletters, flyers, and other media outlets? You will need to meet with your marketing and publications experts to plan how you will market your emerging technology initiatives along with your costs and who will pay them.

7. Who is your audience and how can you engage them? This is the one of the most important areas to address in your proposal to present to your stakeholders. Without our patrons, there is no library. You will need to determine who your audience is and how you can utilize the emerging technologies to assist them. Are they K to 12 students, adults who will be displaced by these technologies, technology novices who want to learn more about these technologies, or university faculty and/or students who want to use the technology for their projects? You can address all of these potential audiences in your proposal to your stakeholders.

These are just a few tips on how to get stakeholder buy-in for implementing emerging technologies in your library. Feel free to share some of your own successes in getting shareholders on board to implement emerging technologies in your library or resource center. 


\section{EMERGING TECHNOLOGY STAKEHOLDER BUY-IN QUESTIONNAIRE}

I have included questions below that you should follow when you are considering getting your stakeholders on board to implement new emerging technologies in your library. If you address all of these, you have a very good chance of getting your stakeholders on board to support your initiatives.

1. What technologies do you want to implement in your library/resource center and why do you want them?

2. Who are your stakeholders and what are their backgrounds?

3. Why should your stakeholders support your technology initiatives?

4. What is your budget for your new technology initiatives?

5. What training is needed to support these initiatives, who will provide the training, what are the costs, and who will pay for the training?

6. How will you market these technology initiatives, what are the costs, and who will pay for them?

7. Did you perform a cost-benefit-analysis for these technology initiatives?

8. Are there legal fees? If so, what are they, and who will pay for them?

9. What are the risks?

10. What are the returns on the investment (ROI)?

11. What strategic partnerships can you establish?

12. What is your timeline for implementing these technology initiatives? 